Bilingualism: Language and Cognition 21 (4), 2018, 867-879 (C) Cambridge University Press 2018. This is an Open Access article, distributed under the terms of the Creative Commons Attribution licence (http://creativecommons.org/licenses/by/4.0/), which permits unrestricted re-use, distribution, and reproduction in any medium, provided the original work is properly cited. doi:10.1017/S1366728918000020

RESEARCH NOTE

\section{From Bilingualism to Bilingualisms: Bilingual experience in Edinburgh and Singapore affects attentional control differently}

\author{
SEOK HUI OOI \\ School of Philosophy, Psychology \& Language Sciences, The \\ University of Edinburgh \\ Department of Psychology, National University of Singapore \\ WIN STON D. GOH \\ Department of Psychology, National University of Singapore \\ ANTONELLA SORACE \\ School of Philosophy, Psychology \& Language Sciences, The \\ University of Edinburgh \\ THOMAS H. BAK \\ School of Philosophy, Psychology \& Language Sciences, The \\ University of Edinburgh
}

(Received: April 4, 2017; final revision received: December 26, 2017; accepted: January 6, 2018; first published online 13 March 2018)

Recent theories propose that language-switching in bilinguals influences executive control. We investigated whether switching behaviour, shaped by the bilingual's interactional context as well as personal preferences impacted attentional control. We compared four groups - (i) Edinburgh monolinguals, (ii) Edinburgh non-switching late bilinguals, (iii) Edinburgh non-switching early bilinguals, and (iv) Singapore switching early bilinguals - on two tasks of attentional control. Effects of interactional context were observed, with Singapore bilinguals performing better on conflict resolution in the Attention Network Task and Edinburgh late bilinguals on attentional switching in the Elevator reversal (Test of Everyday Attention) subtest. Our results suggest that the interactional context of bilinguals could impact attentional control differently.

Keywords: bilingualism, attentional control, interactional context, switching

\section{INTRODUCTION}

\subsection{Theoretical background}

There is conflicting evidence on whether managing multiple languages influences non-linguistic cognitive control. On one hand, bilinguals have been reported to outperform monolinguals on a range of tasks tapping executive control, such as the Simon task (Bialystok, Craik, Klein \& Viswanathan, 2004), flanker tasks (Costa, Hernández, Costa-Faidella \& Sebastián-Gallés, 2009), Stroop task (Hernández, Costa, Fuentes, Vivas \& Sebastian-Galles, 2010) and task-switching (Prior \& Macwhinney, 2010). Based on these results, it has

This work was supported by the PPLS Research Support Grants from the University of Edinburgh and the AHRC Open World Research Initiative Grant "Multilingualism: Empowering Individuals, Transforming Societies (MEITS)" AH/N004671/1. We would like to thank all PPLS IT staff for their kind support with computing issues, and also Yushi Zhang for helping with data collection. The first author is greatly indebted to Mariana Vega-Mendoza for her immense help and support towards this study. We would also like to thank Ian Deary for his comments on the suitability of adopting Set 2 on the Raven's Matrices as a background measure. been suggested that bilinguals show a better ability in tasks tapping on response inhibition and set-shifting. On the other hand, differences between monolinguals and bilinguals on executive control have not been consistently replicated, leading researchers to argue that these group differences are not robust (Paap, Johnson \& Sawi, 2014) and may be confounded by other variables or emerge only in specific groups (Bak, 2016). Some studies have found that monolingual-bilingual differences were attenuated when groups were matched on general ability (Duñabeitia, Hernández, Antón, Macizo, Estévez, Fuentes \& Carreiras, 2014) or socioeconomic background (Morton \& Harper, 2007). Other research groups have reported that bilingual advantages are more evident when attentional demands are sufficiently high, such as under high-monitoring conditions (Costa et al., 2009), or under high working memory demands (Bialystok et al., 2004; Jiao, Liu, Wang \& Chen, 2017; Morales, Calvo \& Bialystok, 2013). Qu, Low, Zhang, Li, and Zelazo (2015) further argued that bilinguals show smaller switch costs and mixing costs than monolinguals when task demands were considered, and proposed that the bilingual advantage reflects a better ability in efficiently managing limited cognitive resources to fulfil goals.

Address for correspondence:

Seok Hui Ooi, Department of Psychology, National University of Singapore, Block AS4, 9 Arts Link, Singapore 117570

seok.hui@nus.edu.sg

Supplementary material can be found online at https://doi.org/10.1017/S1366728918000020 
One other possible reason for these divergent findings is that bilinguals vary on a range of factors which might influence their linguistic as well as non-linguistic performance. One of the bilingualism factors that has come under closer investigation in recent years is that of switching frequency. Bilinguals who switch between their languages frequently have been reported to show smaller switch costs in a colour-shape task switching paradigm than those who switch less frequently (Prior \& Gollan, 2011). Similarly, Verreyt and colleagues (Verreyt, Woumans, Vandelanotte, Szmalec \& Duyck, 2015) found that high-switching bilinguals performed better than both monolinguals and low-switching bilinguals on the Simon and flanker tasks. The results showed that effects of switching in language extend beyond the linguistic domain and also influence performance on tasks tapping inhibitory control.

Complementary to switching frequency is the notion of the interactional context of bilinguals, proposed in the adaptive control hypothesis $(\mathrm{ACH}$; Green \& Abutalebi, 2013). Critically, it should be noted that though the concepts of switching frequency and interactional context are closely related, they are NOT identical. Switching frequency differentiates bilinguals on a QUANTITATIVE measure, i.e., high vs. low frequency, whereas interactional context places less emphasis on how often switching occurs and instead highlights the QUALITATIVE context of how bilinguals engage switching. In the ACH, Green and Abutalebi (2013) described three interactional contexts: In a singLE-LANGUAGE CONTEXT, bilinguals use their two languages in distinct environments and with distinct people. Here, there is little overlap between the bilingual's languages. In contrast, an overlap of languages occurs in the DUAL-LANGUAGE CONTEXT and DENSE CODE-SWITCHING CONTEXT. In both these contexts, bilinguals switch between their languages but the boundary between languages is clearer in the dual-language context, with switching occurring more often between sentences rather than within a single sentence. This is contrasted with the dense codeswitching context, in which language switches happen within a single utterance. It is also common in dense code-switching to see the intermarrying of syntactic and morphological structures between languages, such as is reflected in the term choisieren, which is formed by adding a German particle (-ieren) to the French verb choisir, to choose (Green \& Abutalebi, 2013).

The ACH (Green \& Abutalebi, 2013) proposes that distinct interactional contexts place differential cognitive demands on language control processes, such as interference control and response inhibition. If cognitive control processes underlying switching behaviour in single-language, dual-language and dense code-switching contexts are indeed different, then these differences may generalise to non-linguistic domains, in which case bilinguals may show differences in executive control amongst themselves, depending on which interactional context they engage in. Of the few studies that have specifically examined the role of interactional context on executive control, Hartanto and Yang (2016) reported that bilinguals in a dual-language context showed smaller switch costs in a colour-shape switch task than those in a single-language context. These results are largely in agreement with the findings from studies examining the role of switching frequency as discussed above.

We consider switching frequency and interactional context as analogous but discrete factors that could each exert their own influences on executive control. Therefore, in this study, we aimed to approach the investigation of switching behaviour and its effects on attentional control with a specific focus on interactional context. To this end, we compared performance on two tasks of attentional control between bilingual groups in Edinburgh and Singapore. While both places have produced studies investigating the influence of bilingualism on executive control (Bak, Vega-Mendoza \& Sorace, 2014; Hartanto \& Yang, 2016; Qu et al., 2015; Vega-Mendoza, West, Sorace \& Bak, 2015; Yow \& Li, 2015), to date no studies have made a systematic comparison between populations in the two places. Due to the contrasting sociolinguistic environments in Edinburgh and Singapore, bilinguals in these places engage their languages differently, with a predominantly single-language context in Edinburgh bilinguals and a dual-language/dense codeswitching context in Singapore bilinguals. The linguistic environments of Edinburgh and Singapore are described in greater detail in the next section, 1.2: Language use in

\section{Edinburgh and Singapore.}

As mentioned earlier, since language switching behaviour can be shaped both by personal tendencies as well as the bilingual's interactional context, we further supplemented the investigation of interactional context (Edinburgh vs. Singapore comparison) by also examining the relationship between self-reported switching behaviour and task performance. We asked participants to report two different aspects of their switching behaviour, SWITCHING TENDENCY and SWITCHING FREQUENCY. Switching tendency considers the more qualitative aspect of switching, asking participants to indicate if they kept to a single language or switched between languages when speaking to other bilinguals; switching frequency, on the other hand, provides a more quantitative measure, with participants indicating how often they engaged in switching. More details on these measures are provided below in the methods section. We therefore attempted to employ a more holistic approach in the study of switching behaviour by considering their effects at both the general level of linguistic environment, as well as at a more specific level of individual switching preferences. 
We selected two attentional tests that have reported differences between mono- and bilingual subjects, the visual Attention Network Task (ANT; Fan, McCandliss, Sommer, Raz \& Posner, 2002) and the auditory ElEVATOR TASK (Test of Everyday Attention [TEA], Robertson, Nimmo-Smith, Ward \& Ridgeway, 1994) for the following reasons. Firstly, these tasks tap on different components of attentional control and have been commonly used in monolingual-bilingual comparisons with reported differences between groups (Bak et al., 2014; Costa, Hernández \& Sebastián-Gallés, 2008; Poarch \& van Hell, 2012; Tao, Marzecová, Taft, Asanowicz \& Wodniecka, 2011; Vega-Mendoza et al., 2015; but see Clare, Whitaker, Martyr, Martin-Forbes, Bastable, Pye, Quinn, Thomas, Mueller Gathercole \& Hindle, 2016; Hindle, Martin-Forbes, Bastable, Pye, Martyr, Whitaker, Craik, Bialystock, Thomas, Mueller Gathercole \& Clare, 2015 for counterarguments). The ANT yields three indices of attentional control: alerting, orienting, and conflict resolution, while the TEA Elevator contains three subtests which assess auditory sustained attention, auditory selective attention, and auditory attentional switching (Robertson et al., 1994). These tasks are described in detail in 2.3: Experimental Tasks.

Secondly, given that language engages not only visual components (i.e., reading and writing) but also auditory ones (i.e., speaking and hearing), these tasks supplement each other as the ANT and TEA Elevator tap visual and auditory processing respectively, thereby allowing us to investigate attentional control in the two distinct modalities in which language is grounded. Thirdly, whereas the ANT is motivated by a theoretical framework of attention and commonly used in an experimental setting, the TEA was designed to simulate day-to-day activities and thus assesses attention using an ecological approach. The use of these tests in conjunction therefore offers a more varied approach in assessing attentional control.

\subsection{Language use in Edinburgh and Singapore}

Both Edinburgh (United Kingdom) and Singapore are high-income economies (The World Bank, 2017) and classified as countries with very high human development on the Human Development Index (United Nations Development Programme, 2015), indicators that the two places have a comparable standard and quality of life. With regard to language use, however, there are marked differences between them. Firstly, the general language environment in Edinburgh is monolingual, with English being the predominant language. Although Gaelic has the status of an official language in Scotland, it is spoken by only about $1 \%$ of the population (National Records of Scotland, 2015), with more than half of them living on the Western Isles. In Edinburgh, the presence of Gaelic is confined to specific places and contexts, such as the Scottish Parliament and educational establishments. In contrast, Singapore has a multilingual environment with four official languages, English, Mandarin, Malay and Tamil. It has also adopted a mandatory bilingual education policy for the past 50 years and thus the majority of its population is bilingual in English and one of the three other official languages. Approximately $74 \%$ of the population are Mandarin speakers, $13 \%$ Malay speakers, and 9\% Tamil speakers (Singapore Department of Statistics, 2016). Because languages are commonly shared between people, code-switching is highly prevalent in everyday life and has been widely studied as a notable characteristic of the Singapore linguistic environment (Bokhorst-Heng \& Caleon, 2009; Foley, 1988, 1998; Kamwangamalu \& Lee, 1991; Ong \& Zhang, 2010; Xie \& Cavallaro, 2016).

Secondly, the multilingual environment of Singapore means that languages are acquired early (if not from birth), partly through immersion, partly through the schooling system. On the other hand, early bilingualism is uncommon in the native Edinburgh population and most functional bilinguals acquire their second language later in life either through immersion or formal studying. Hence, Edinburgh and Singapore bilinguals differ not only in switching behaviour but also in their age of L2 acquisition (AoA). To distinguish the effects of switching and of AoA, we further included a nonswitching, early acquisition group from Edinburgh ${ }^{1}$ recruited from the same university though most of them grew up in places other than Edinburgh due to reasons mentioned above. This resulted in four groups of participants: English monolinguals (ML), Edinburgh late bilinguals (ELB), Edinburgh early bilinguals (EEB), and Singapore early bilinguals (SB). A comparison between these groups on the key language variables is shown in Table 1.

In view of the evidence suggesting that monolingualbilingual comparisons are often confounded by the factor of immigration status (Fuller-Thomson \& Kuh, 2014; Paap, Johnson \& Sawi, 2015), all bilinguals recruited in the current study were from a NON-IMMIGRANT population. More details about bilinguals in the respective groups will be provided in the Methods section below.

To summarise, the aim of the current study was to examine the relationship between attention and switching, as determined: (i) by the interactional context of bilinguals in Edinburgh and Singapore, (ii) by selfreported switching behaviour. Since there is little literature

\footnotetext{
1 Due to the bilingual education policy, there are no late bilinguals in the native Singapore population.
} 
Table 1. Summary comparison between groups on key variables.

\begin{tabular}{llll}
\hline \hline & $\begin{array}{l}\text { Interactional } \\
\text { context }\end{array}$ & AoA & $\begin{array}{l}\text { Native } \\
\text { population? }\end{array}$ \\
\hline$M L$ & - & - & $\sqrt{ }$ \\
$E L B$ & single language & late & $\sqrt{ }$ \\
$E E B$ & single language & early & $(\sqrt{ })^{*}$ \\
$S B$ & dual language/ & early & $\sqrt{ }$ \\
& dense code-switching & & \\
\hline
\end{tabular}

*a subset of participants was born and raised in the U.K., and the rest within a monolingual community in either Europe or the United States (more details in 2.1: Participants)

on the effects of interactional context on attentional control performance, we did not make specific predictions with regard to group performance, but instead asked if: (i) bilingual groups in different interactional contexts differed from each other, (ii) self-reported switching measures correlated with the various ANT and TEA Elevator test components.

\section{METHODS}

\subsection{Participants}

Monolinguals and Edinburgh bilinguals were recruited from the University of Edinburgh and Singapore bilinguals from the National University of Singapore. Both universities involved are top-tiered universities with comparable international rankings (Quacquarelli Symonds [QS] Top Universities, 2017; Times Higher Education, 2017) and have similar student numbers (National University of Singapore, 2017a, 2017b; The University of Edinburgh, Governance and Strategic Planning, 2017). The relevant comparisons are given in Table 2 . The study was approved by the ethics committees of both universities and a total of 245 students participated in the study. Participant background demographics are given in Table 3.

All ML, ELB, and SB participants were native speakers of English. Given the small numbers of early bilinguals in the native Edinburgh population as described above, it would not have been possible to apply the same criteria to the EEB. Accordingly, this group consisted of individuals who grew up in different countries speaking a variety of languages in addition to English, but all of them were born and raised within a monolingual community: a subset of them in the U.K. (19.2\%), others in Europe (65.4\%) or the United States (15.4\%). L2s of bilinguals included the following: (in ELB) Spanish, German, French, Chinese, Japanese; (in SB) Chinese, Malay; (in EEB) French, German, Italian, Chinese, Spanish,
Table 2. Comparison between Edinburgh and Singapore and the respective universities.

\begin{tabular}{|c|c|c|}
\hline & Edinburgh & Singapore \\
\hline World bank classification & high $^{\mathrm{i}}$ & high \\
\hline Human development index & $\begin{array}{l}0.909 \\
\left(\text { very high }{ }^{\mathrm{i}}\right)\end{array}$ & $\begin{array}{l}0.925 \\
\text { (very high) }\end{array}$ \\
\hline Number of (full) universities & $4^{\mathrm{ii}}$ & 6 \\
\hline $\begin{array}{l}\text { International ranking } \\
\text { QS; Times }\end{array}$ & $23 ; 27$ & $15 ; 24$ \\
\hline No. of students ${ }^{\mathrm{iii}}$ & 39,576 & 38,596 \\
\hline
\end{tabular}

ibased on ratings of the United Kingdom

ii total number of universities in East Lothian, the council area to which Edinburgh belongs

iii includes full-time and part-time undergraduates and postgraduates

Polish, Greek, Punjabi, Urdu, Czech, Swedish, Russian, Hungarian, Romanian, Serbian, Slovenian. The detailed language combinations of bilinguals in the respective groups are given in Appendix A (Supplementary Materials).

As part of the recruitment process, information on language usage and switching behaviour was obtained from all participants. All ELB confirmed that they used their L2s exclusively with a specific group of people, mainly restricted to language classmates in school. To match the EEB group as closely as possible to ELB on their general linguistic environment and thereby interactional context, we therefore only recruited EEB who described themselves as non-switching bilinguals and reported using their languages within distinct contexts with little overlap between them, such as French at home and English in the community.

All ML had been exposed to second language learning as part of their secondary school curriculum but none had functional proficiency in an L2, with usage limited to classroom learning. ELB were university language majors at an intermediate-advanced level or above. The majority of them had spent a year abroad in a country where their L2 was the official language spoken, either in university or on an internship. ML controls were matched for subject of study and consisted of arts/humanities majors in English Literature, Linguistics or History. SB and EEB were predominantly humanities students, but also included participants from other disciplines of study. ELB began L2 learning as part of their secondary school curriculum from age 13, but only started intensive study upon enrolling in university around the age of 17-18. SB were either simultaneous bilinguals $(88.4 \%)$ or had acquired their second language before the age of 5; EEB were either simultaneous bilinguals (56\%) or had acquired their second language before the age of 6 . 
Table 3. Participant demographics and self-reported language proficiency. SDs are given in parentheses.

\begin{tabular}{|c|c|c|c|c|}
\hline & ML & ELB & EEB & SB \\
\hline \multirow[t]{2}{*}{$n(\%$ female $)$} & 64 & 63 & 48 & 70 \\
\hline & $(73.4)$ & (74.6) & $(72.9)$ & $(71.4)$ \\
\hline \multirow[t]{2}{*}{ Age (yrs) } & 21.4 & 22.1 & 21.3 & 21.8 \\
\hline & $(3.0)$ & $(3.0)$ & $(3.1)$ & $(2.2)$ \\
\hline \multirow[t]{2}{*}{ Raven's $A P M$} & 15.4 & 16.3 & 17.7 & 17.1 \\
\hline & (3.8) & (3.5) & $(4.3)$ & $(3.6)$ \\
\hline \multirow[t]{2}{*}{ Gaming frequency ${ }^{\mathrm{i}}$} & 1.43 & 1.57 & 1.54 & 1.26 \\
\hline & $(1.29)$ & $(1.30)$ & $(1.35)$ & (1.38) \\
\hline \multirow[t]{2}{*}{ L1 speaking } & 4.00 & 4.00 & 4.00 & 3.89 \\
\hline & $(0.00)$ & $(0.00)$ & $(0.00)$ & $(0.32)$ \\
\hline \multirow[t]{2}{*}{ L1 understanding } & 4.00 & 4.00 & 3.96 & 3.89 \\
\hline & $(0.00)$ & $(0.00)$ & $(0.20)$ & $(0.20)$ \\
\hline \multirow[t]{2}{*}{ L1 reading } & 4.00 & 4.00 & 3.94 & 3.86 \\
\hline & $(0.00)$ & $(0.00)$ & $(0.32)$ & $(0.35)$ \\
\hline \multirow[t]{2}{*}{ L1 writing } & 4.00 & 4.00 & 3.79 & 3.77 \\
\hline & $(0.00)$ & $(0.00)$ & $(0.66)$ & $(0.46)$ \\
\hline \multirow[t]{2}{*}{ L2 speaking } & - & 2.95 & 3.85 & 3.63 \\
\hline & & $(0.59)$ & $(0.36)$ & $(0.54)$ \\
\hline \multirow[t]{2}{*}{ L2 understanding } & - & 3.24 & 3.94 & 3.71 \\
\hline & & $(0.59)$ & $(0.25)$ & $(0.52)$ \\
\hline \multirow[t]{2}{*}{$L 2$ reading } & - & 3.08 & 3.74 & 3.49 \\
\hline & & $(0.71)$ & $(0.61)$ & $(0.76)$ \\
\hline \multirow[t]{2}{*}{ L2 writing } & - & 2.77 & 3.47 & 3.11 \\
\hline & & $(0.73)$ & $(0.75)$ & $(0.91)$ \\
\hline \multirow[t]{2}{*}{$A o A$} & - & 12.9 & 1.2 & 0.7 \\
\hline & & (4.7) & (1.6) & (1.6) \\
\hline \multirow[t]{2}{*}{ Switching tendency ${ }^{\mathrm{ii}}$} & - & 2.6 & 2.6 & 2.7 \\
\hline & & (0.6) & $(0.9)$ & $(0.9)$ \\
\hline \multirow[t]{2}{*}{ Switching frequency ${ }^{\text {iii }}$} & - & 3.2 & 3.4 & 4.2 \\
\hline & & (1.2) & (1.4) & (1.1) \\
\hline
\end{tabular}

${ }^{\mathrm{i}}$ This was scored on a scale of 0: once a year or less, 1: few times a year, 2: few times a month, 3: few times a week, and 4: daily ${ }^{\mathrm{ii}}$ Rated on a Likert scale of 1: always sticking to one language, 2: frequently sticking to one language, 3: frequently mixing languages, and 4: always mixing languages.

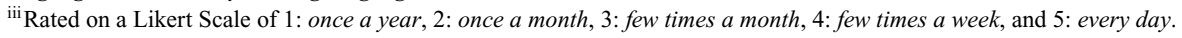

\subsection{Background Measures}

\section{L2 measures, switching behaviour, and gaming frequency}

Descriptive statistics ${ }^{2}$ are presented in Table 3. Participants rated themselves on their proficiency in speaking, understanding, reading, and writing in each of their lan-

2 Items were added to the background questionnaire to obtain more relevant information as data collection progressed. Therefore, data on video-gaming and switching frequency were not collected from a subset of participants. The Raven's APM was also incorporated at a slightly later point. The number of missing data points on the respective items are as follows: guages (see Appendix B, Supplementary Materials). Selfreported language switching measures were collected via

\begin{tabular}{llllll}
\hline \hline & $\mathrm{ML}$ & $\mathrm{ELB}$ & $\mathrm{EEB}$ & $\mathrm{SB}$ & Total \\
\hline Raven's & 16 & 6 & 1 & 4 & 27 \\
APM & $(25.0 \%)$ & $(9.5 \%)$ & $(2.1 \%)$ & $(5.7 \%)$ & $(11.0 \%)$ \\
Gaming & 22 & 12 & 2 & 4 & 40 \\
frequency & $(34.4 \%)$ & $(19.0 \%)$ & $(4.2 \%)$ & $(5.7 \%)$ & $(16.3 \%)$ \\
Switching & - & 1 & 6 & 4 & 11 \\
tendency & & $(1.6 \%)$ & $(12.5 \%)$ & $(5.7 \%)$ & $(6.1 \%)$ \\
Switching & - & 19 & 7 & 6 & 32 \\
frequency & & $(30.2 \%)$ & $(14.6 \%)$ & $(8.6 \%)$ & $(17.7 \%)$ \\
\hline \hline
\end{tabular}




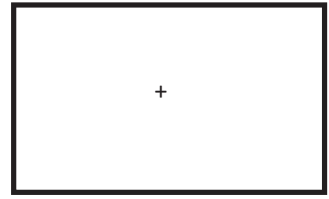

no cue

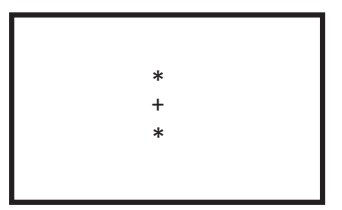

double cue

(a)

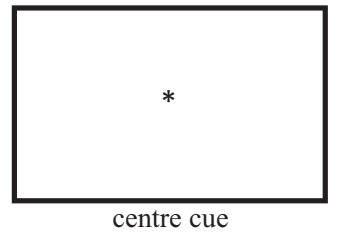

centre cue

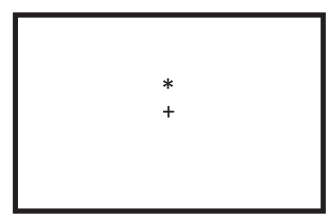

spatial cue

(b)

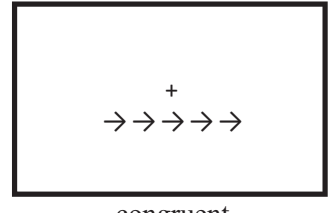

congruent

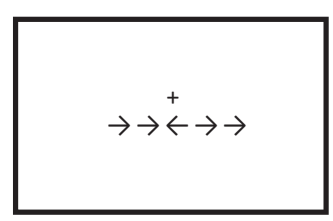

incongruent

(c)

Figure 1. Trial types and indices in the ANT. (a) Alerting effect. (b) Orienting effect. (c) Conflict effect.

two items in the switching questionnaire, (adapted from Rodriguez-Fornells, Krämer, Lorenzo-Seva, Festman \& Münte, 2012); the first asked about participants' switching tendency (Q3, bilingual switching questionnaire, Appendix B, Supplementary Materials), with participants stating which of the following best described the way they used their languages with other bilinguals: always sticking to one language, frequently sticking to one language, frequently mixing languages, always mixing languages. The second item on switching frequency (Q4, bilingual switching questionnaire) asked participants to state how frequently they mixed or switched between languages with these bilinguals (once a year, once a month, few times a month, few times a week, every day).

In line with studies showing that cognitive control can be enhanced by video-gaming experience (Dye, Green \& Bavelier, 2009; Wilms, Petersen \& Vangkilde, 2013), we also asked participants to report their video-gaming frequency.

\section{Raven's Advanced Progressive Matrices (APM)}

The APM (J. C. Raven \& Foulds, 1962) was administered as a measure of nonverbal general intelligence ${ }^{2}$. Previous studies (Costa et al., 2009; Paap \& Greenberg, 2013) have typically used Set 1 which consists of 12 items; however, as pilot testing showed that our participants were performing at ceiling on this set, we adopted Set 2 of the matrices with a time limit of 10 minutes.

\subsection{Experimental Tasks}

\section{ANT}

Participants saw a row of horizontally aligned arrows appearing either above or below a fixation cross and indicated if the central arrow pointed to the left or right. Trials could be (i) congruent, i.e., $\rightarrow \rightarrow \rightarrow \rightarrow \rightarrow$, (ii) incongruent, i.e., $\rightarrow \rightarrow \leftarrow \rightarrow \rightarrow$, or (iii) neutral, i.e., $-\rightarrow \rightarrow-$. There were four cueing conditions: spatial, double, centre, and no cue. The three indices of alerting, orienting, and conflict resolution are given by differences in reaction times (RTs) between the following trial types (Figure 1): (i) Alerting effect - no cue/double cue, (ii) Orienting effect - centre/spatial, and (iii) Conflict effect incongruent/congruent.

Participants were given a practice block consisting 24 trials followed by three experimental blocks of 96 trials each. Feedback on performance was given only in the practice blocks.

\section{TEA Elevator Task}

The TEA (Robertson et al., 1994) is a well-established clinical tool used to evaluate attention and the Elevator Task comprises three subtests which assesses different aspects of auditory attention, detailed below. Tones were presented via speakers:

(a) Counting subtest (7 trials) assesses sustained attention. Participants were asked to count the number of beeps presented in a single trial.

(b) Distraction SUbTest (10 trials) assesses auditory selective attention. Both "basic" tones (as presented in the Counting subtest) and high tones were presented and participants were asked to count only the basic tones, ignoring high ones.

(c) Reversal subtest (10 trials) assesses attentional switching. Three types of tones - high, low, and mid (basic) - were presented and participants had to count either upwards (as prompted by high tones) or downwards (as prompted by low tones) according to cue.

\subsection{Statistical analyses}

Data with a non-normal distribution were analysed using non-parametric tests and followed up with pairwise 
comparisons adjusted for $p$-values where relevant. This included data on L2 measures, video-gaming frequency, gender distribution, and accuracy rates. RT data was analysed with the appropriate analysis of variance (ANOVAs), described in further detail in the relevant sections below. The correlations between selfreported switching tendency/ switching frequency and performance on the respective ANT indices/ TEA subtests were analysed using Spearman's correlational analysis.

\section{RESULTS}

\subsection{Background Measures}

\section{Language measures}

There were no group differences on age $[F(3,241)=$ $1.22, p=.303]$, gender distribution $\left[\chi^{2}(3)=0.128, p\right.$ $=.988]$, and video-gaming frequency $[H(3)=2.52, p=$ $.472]$. Self-ratings on L1 proficiency were not analysed as all ML and ELB participants rated themselves a " 4 " on all components of speaking, understanding, reading, and writing.

Bilingual groups differed on self-rated L2 proficiency in speaking $[H(2)=64.0, p<.001]$, understanding $[H(2)$ $=49.9, p<.001]$, reading $[H(2)=30.1, p<.001]$, and writing $[H(2)=21.6, p<.001]$. Pairwise comparisons adjusted for $p$-values showed that ELB rated themselves lower than both SB and EEB on all aspects (ELB compared to SB: speaking and understanding, $p \mathrm{~s}<.001$; reading, $p=.001$; writing, $p=.021$; ELB compared to EEB: speaking, understanding, reading, writing, all $p \mathrm{~s}$ $<.001)$.

There were no differences between groups on self-rated switching tendency $[H(2)=1.88, p=.390]$, but groups differed on self-rated switching frequency, $H(2)=22.3$, $p<.001$. SB reported switching more frequently than both $\operatorname{ELB}(p<.001)$ and $\operatorname{EEB}(p=.003)$.

\section{Raven's APM}

Raven's APM scores were analysed using a one-way ANOVA. Group differences were observed $[F(3,215)=$ $3.47, p=.017]$ and Tukey's HSD revealed that ML scored lower than $\operatorname{EEB}(p=.017, d=0.56)$. All other group comparisons were not statistically significant.

\section{Supplementary analyses}

Previous norming exercises on the APM have documented differences in performance across disciplines, with a trend for higher scores in science/engineering majors as compared to arts and humanities majors (J. Raven, Raven \& Court, 1998). To explore if the observed group differences in our sample could have been driven by the higher proportion of science/engineering students in the SB and EEB groups, we performed a followup analysis excluding science/engineering majors such
Table 4. Number (percentage) of participants in science and engineering disciplines by group.

\begin{tabular}{lll}
\hline \hline & $\begin{array}{l}n(\%) \text { of science/ } \\
\text { engineering majors }\end{array}$ & $\begin{array}{l}\text { Raven's scores } \\
\text { excluding (SD) }\end{array}$ \\
\hline ML & 0 & 15.4 \\
& $(0.0 \%)$ & $(3.8)$ \\
ELB & 0 & 16.2 \\
& $(0.0 \%)$ & $(3.5)$ \\
EEB & 19 & 17.5 \\
& $(39.6 \%)$ & $(4.7)$ \\
SB & 25 & 16.5 \\
& $(35.7 \%)$ & $(3.1)$ \\
\hline \hline
\end{tabular}

that the subjects studied were comparable. This analysis revealed no significant group differences in performance, $F(3,170)=1.87, p=.137$. The number of participants excluded in each group and the average scores after this exclusion is given in Table 4.

\subsection{Experimental Tasks}

Given the group differences on APM scores, we analysed task performance both using the full sample, and also on a subset excluding science/engineering students. Both analyses revealed the same pattern of results; hence we report results on the full set of data here.

\section{ANT}

Overall accuracy rates were analysed using the KruskalWallis test and mean RT data using a one-way betweengroup ANOVA. Performance on the three respective ANT indices was analysed using a 2 (trial-type, withingroup variable) $\times 4$ (group, between-group variable) mixed-ANOVA (ANT alerting: no-cue vs. double cue; ANT orienting: centre cue vs. spatial cue; ANT conflict: incongruent trial vs. congruent trial). Significant interaction effects were followed-up by a one-way between-group ANOVA with the corresponding ANT index as the dependant variable.

\section{Overall performance}

Mean RTs were calculated for each individual participant and data was trimmed using a 3-SD criterion (this discarded $1.30 \%$ of total trials). Three participants had an overall accuracy that was 3 SDs or more below the average mean of all participants $(<91.7 \%)$, thus we analysed task performance both with and without their data. Both analyses showed the same results and hence their data were retained.

Overall accuracy and mean RTs by group is illustrated in Figure 2. There were no group differences in overall 


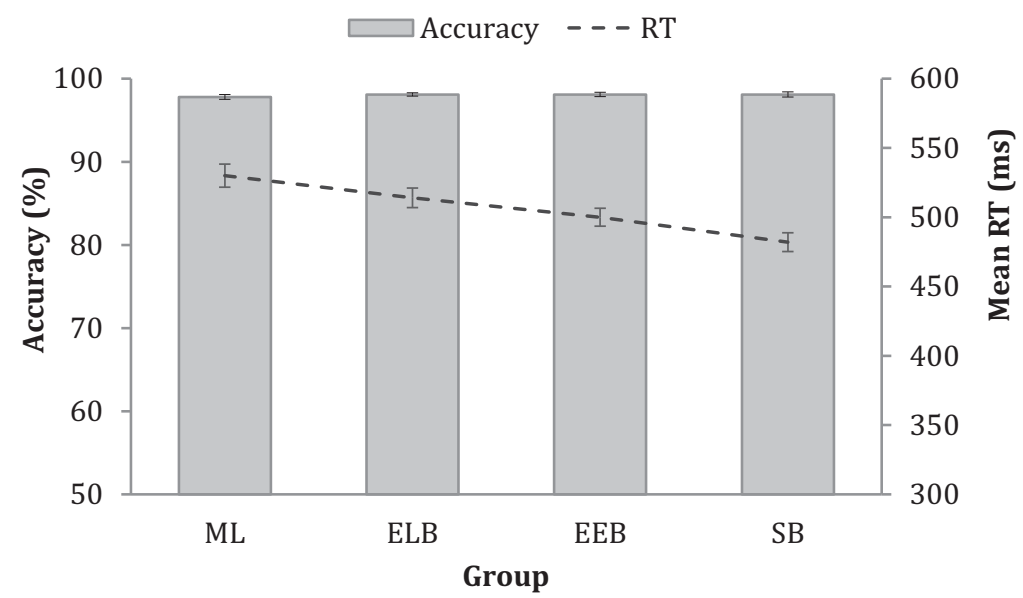

Figure 2. Overall performance on the ANT by group, collapsed across trial- and cue-type. Error bars represent \pm 1 SE.

Table 5. ANT indices by group. SDs are given in parentheses.

\begin{tabular}{lllll}
\hline \hline & $\boldsymbol{M L}$ & $\boldsymbol{E L B}$ & $\boldsymbol{E E B}$ & $\boldsymbol{S B}$ \\
\hline No Cue & 561 & 552 & 528 & 519 \\
& $(72)$ & $(61)$ & $(47)$ & $(61)$ \\
Double Cue & 523 & 514 & 492 & 474 \\
& $(64)$ & $(59)$ & $(45)$ & $(53)$ \\
\hline Alerting Effect & $\mathbf{3 8}$ & $\mathbf{3 8}$ & $\mathbf{3 7}$ & $\mathbf{4 5}$ \\
& $\mathbf{( 2 6 )}$ & $\mathbf{( 2 7 )}$ & $\mathbf{( 1 7 )}$ & $\mathbf{( 2 3 )}$ \\
\hline Centre Cue & 530 & 516 & 497 & 484 \\
& $(69)$ & $(58)$ & $(47)$ & $(59)$ \\
Spatial Cue & 492 & 482 & 464 & 452 \\
& $(60)$ & $(54)$ & $\mathbf{( 4 6 )}$ & $(60)$ \\
\hline Orienting Effect & $\mathbf{3 7}$ & $\mathbf{3 4}$ & $\mathbf{3 3}$ & $\mathbf{3 2}$ \\
& $(\mathbf{2 4 )}$ & $\mathbf{( 2 3 )}$ & $\mathbf{( 2 1 )}$ & $\mathbf{( 2 2 )}$ \\
\hline Incongruent & 603 & 579 & 564 & 543 \\
& $(8.6)$ & $(8.3)$ & $(9.6)$ & $(8.0)$ \\
Congruent & 505 & 481 & 473 & 460 \\
& $(7.2)$ & $(7.0)$ & $(8.1)$ & $(6.8)$ \\
\hline Conflict Effect & $\mathbf{9 8}$ & $\mathbf{9 8}$ & $\mathbf{9 1}$ & $\mathbf{8 3}$ \\
& $\mathbf{( 2 7 . 0 )}$ & $\mathbf{( 2 7 . 7 )}$ & $\mathbf{( 2 6 . 7 )}$ & $\mathbf{( 2 6 . 4 )}$ \\
\hline \hline
\end{tabular}

${ }^{a, b}$ The difference between groups was statistically significant.

accuracy $[H(3)=2.37, p=.498]$, but differences were observed in mean RTs $[F(3,243)=8.28, p<.001]$. Tukey's HSD revealed that ML were slower than both $\operatorname{EEB}(p=.018, d=0.56)$ and $\mathrm{SB}(p<.001, d$ $=0.72)$, and that ELB were slower than $\mathrm{SB}(p=$ $.004, d=0.60)$. All other group differences were not significant. The same pattern of group differences on mean RTS was observed across all trial types, hence this will not be repeated in the subsequent sections. Mean RTs on the respective trial types are given in Table 5.

\section{Alerting network}

The ALERTING EFFECT was significant, with higher accuracy on double-cue trials (Mean $=96.9 \%, \mathrm{SD}=$ $3.0 \%$ ) than no-cue trials (Mean $=96.1 \%, \mathrm{SD}=2.8 \%$ ), $z$ $=9.80, p<.001$. Participants were also faster on doublecue than no-cue trials $\left[F(1,240)=627.5, p<.001, \eta_{p}{ }^{2}=\right.$ .723], but there was no interaction between trial type and group $\left[F(3,240)=1.78, p=.152, \eta_{p}{ }^{2}=.022\right]$. Group differences were observed on mean RTs $[F(3,240)=8.68$, $p<.001, \eta_{p}{ }^{2}=.098$ ], with the same pattern reported in the main RT analysis above. 


\section{Orienting network}

The ORIENTING EFFECT was significant, with higher accuracy on spatial-cue trials (Mean $=97.7 \%, \mathrm{SD}=$ $2.6 \%$ ) than centre-cue trials (Mean $=96.2 \%, \mathrm{SD}=3.2 \%$ ), $z=7.70, p<.001$. On RT data, participants were also faster to respond to spatial-cue trials than centre-cue trials $\left[F(1,240)=553.3, p<.001, \eta_{p}{ }^{2}=.697\right]$. The Trial Type $\times$ Group interaction was not significant, $F(3,240)=1.01$, $p=.390, \eta_{p}{ }^{2}=.012$. Group differences were observed on mean RTs $\left[F(3,240)=7.68, p<.001, \eta_{p}{ }^{2}=.088\right]$.

\section{Executive network}

The CONFLICT EFFECT was significant, with higher accuracy on congruent trials $($ Mean $=98.7 \%, \mathrm{SD}=1.4 \%$ ) than incongruent trials (Mean $=92.8 \%, \mathrm{SD}=5.3 \%$ ), $\%), z=13.2, p<.001$. On RT data, participants were faster on congruent than on incongruent trials, $F(1,240)=$ $2790.9, p<.001, \eta_{p}{ }^{2}=.921$. The main effect of group was significant $\left[F(3,240)=9.01, p=<.001, \eta_{p}{ }^{2}=.101\right]$, as was the Group $\times$ Trial Type interaction, $F(3,240)=4.58, p$ $=.004, \eta_{p}{ }^{2}=.054$. The follow-up one-way ANOVA with the ANT conflict effect as the dependant variable revealed that SB showed a smaller conflict effect compared to both $\operatorname{ML}(p=.006, d=0.59)$ and $\operatorname{ELB}(p=.016, d=0.52)$.

\section{Switching tendency and frequency}

Because group differences were observed on ANT performance, the correlation between self-reported switching behaviour and task performance was investigated within each of the respective bilingual groups (ELB, EEB, SB) using Spearman's correlational analysis. $^{3}$ The Bonferroni correction was applied for multiple comparisons, hence giving a corrected criteria of $p<.01$. In ELB and SB, the correlation between switching tendency and the ANT conflict effect showed a trend towards significance but without reaching it when corrected for multiple comparisons. Switching frequency

3 We also conducted a separate analysis on the correlation between self-reported switching measures and task performance collapsed across bilingual groups. Consistent with the analyses spilt by group, no significant correlation was found between switching tendency or switching frequency and any of the test components and we therefore reported the latter.

\begin{tabular}{lcc}
\hline \hline & Switching tendency & Switching frequency \\
\hline ANT alerting & -.019 & .131 \\
& $(.804)$ & $(.111)$ \\
ANT orienting & .008 & .052 \\
& $(.919)$ & $(.526)$ \\
ANT conflict & -.108 & -.082 \\
& $(.161)$ & $(.318)$ \\
TEA Distraction & -.055 & -.120 \\
& $(.478)$ & $(.146)$ \\
TEA Reversal & .002 & -.042 \\
& $(.984)$ & $(.613)$ \\
\hline \hline
\end{tabular}

Table 6. Correlations between switching tendency and ANT indices/ TEA subtests in ELB, EEB, and SB. p-values are given in parentheses.

\begin{tabular}{lccc}
\hline \hline & ELB & EEB & SB \\
\hline ANT alerting & -.13 & .17 & .06 \\
& $(.302)$ & $(.568)$ & $(.651)$ \\
ANT orienting & -.18 & -.09 & .03 \\
& $(.174)$ & $(.283)$ & $(.804)$ \\
ANT conflict & .27 & -.20 & -.24 \\
& $(.036)$ & $(.194)$ & $(.049)$ \\
TEA Distraction & .01 & .144 & -.08 \\
& $(.916)$ & $(.362)$ & $(.532)$ \\
TEA Reversal & -.18 & -.05 & .17 \\
& $(.158)$ & $(.754)$ & $(.180)$ \\
\hline \hline
\end{tabular}

Note. Performance on TEA Counting was not analysed as this subtest was included as a familiarisation task, hence participants were expected to perform at ceiling.

Table 7. Correlations between switching frequency and the ANT indices/TEA subtests in ELB, EEB, and SB. $p$ values given in parentheses.

\begin{tabular}{lccc}
\hline \hline & ELB & EEB & SB \\
\hline ANT alerting & .11 & .12 & -.02 \\
& $(.469)$ & $(.443)$ & $(.860)$ \\
ANT orienting & -.11 & -.06 & .20 \\
& $(.482)$ & $(.719)$ & $(.111)$ \\
ANT conflict & .17 & -.10 & -.09 \\
& $(.275)$ & $(.542)$ & $(.464)$ \\
TEA Distraction & -.20 & -.04 & -.09 \\
& $(.196)$ & $(.829)$ & $(.494)$ \\
TEA Reversal & -.25 & .02 & .122 \\
& $(.105)$ & $(.894)$ & $(.338)$ \\
\hline \hline
\end{tabular}

was not significantly correlated with any of the indices. Statistics relevant to these analyses are given in Table 6 and Table 7.

\section{TEA Elevator Task}

There were no group differences on the Counting $[H(3)$ $=1.34, p=.719]$ and Distraction subtests $[H(3)=$ 2.24, $p=.525]$, but group differences were found on the Reversal subtest $[H(3)=8.53, p=.036]$. Post-hoc comparisons showed that ELB outperformed ML $(p=$ .022). All other group differences were not significant. Group performance on the respective subtests is illustrated in Figure 3. 


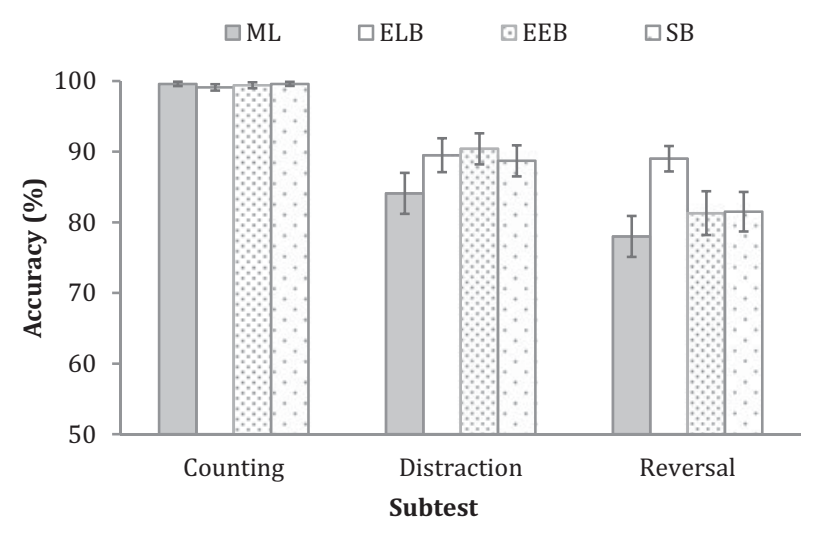

Figure 3. Performance on the respective TEA Elevator subtests by group. Error bars represent $\pm 1 \mathrm{SE}$.

\section{Switching tendency and frequency}

Neither switching tendency nor switching frequency was significantly correlated with performance on the TEA Elevator subtests in all groups (refer to Table 6 and Table 7).

\section{DISCUSSION}

The aim of this study was to examine effects of switching behaviour on attentional control in relation to both the bilingual's interactional context and also to more specific personal tendencies as given by self-reports. Our results showed differences between bilinguals and monolinguals as well as between different bilingual groups. SB outperformed ML and ELB on the ANT conflict index, while ELB were better than ML on the TEA reversal subtest. It is noteworthy that while both the ELB and SB groups showed enhanced attentional control, the superiority in performance was demonstrated on distinct task components. These findings are consistent with the notion put forth by the ACH (Green \& Abutalebi, 2013), which proposes that differential demands are placed on language control processes depending on the nature of the bilingual's interactional context. In the current study, bilinguals who engage in some form of language switching (dual language/ dense code-switching context) were more efficient in resolving conflicting information arising from congruent and incongruent trials, whereas those who use their languages in distinct contexts (singlelanguage context) showed an enhanced ability in auditory attentional switching.

As compared to ELB and SB, the interpretation of performance in the EEB group is less straightforward. Their performance did not differ significantly from either ELB or SB on both the ANT conflict index and TEA reversal: thus one possible interpretation is that they were performing at a level in between that of the two groups.
Since EEB shared greater similarity with ELB in terms of interactional context, but with SB on AoA, this suggests that attentional control could be influenced by an interplay of bilingualism factors; in this case, that of interactional context and AoA. This interpretation would be consistent with the notion that bilingualism is a multi-dimensional construct (Luk \& Bialystok, 2013), and hence the effects of bilingualism on cognition should be considered from multiple aspects.

As a supplementary aim to the investigation of interactional context, we also examined the relationship between self-reported switching behaviour and task performance. We did not find a significant correlation between self-reported measures of switching (switching tendency, switching frequency) and attentional control indices in any of the EEB, ELB, and SB groups. The results thus found some support for an influence of interactional context on attentional control, but not an influence of selfreported switching behaviour.

This study demonstrates both the advantages and the limitations of a comparison of bilingualism across different societies. The main limitation was the inevitable absence of Singapore monolinguals, dictated by the characteristics of the population as all native Singaporeans would have acquired two languages in childhood as a result of the education system and linguistic environment. For the same reason of population characteristics, the EEB group was more heterogeneous compared to the other three groups as they were made up of participants from different countries. Many of them had lived outside their home country while growing up and those experiences might have influenced their cognitive performance. This may partly explain the higher Raven's APM scores in the EEB group as compared to ML, though we note that these group differences were attenuated when the discipline of study was taken in account.

One other limitation of our study was the absence of a comparison between the dual-language context and dense code-switching contexts as this was difficult to distinguish given that the linguistic environment in Singapore makes it likely for bilinguals to engage in both contexts. Future studies making a distinction between these two interactional contexts would help to further clarify how cognitive control demands differ between them. Another interesting comparison that could be made is that between bilinguals who engage in intersentential vs. intrasentential switching. With regard to participant characteristics, although the current study involved individuals recruited from universities in two different countries, we provided information (see 2.1: Participants) explaining that both the universities involved had highly competitive entrance criteria and were comparable in terms of academic standing at the international level. This thereby indicates that the populations from which participants were recruited were comparable on general academic 
achievement and motivation. We were, however, unable to consider all demographic variables (socioeconomic status, musical enrichment, cultural orientation etc.) in depth in the current study, and suggest this as a possible investigation for future studies.

Comparisons between different bilingual populations are bound to be difficult due to multiple intervening variables. However, as bilingualism research is adopting an increasingly global agenda (Abutalebi, Guidi, Borsa, Canini, Della Rosa, Parris \& Weekes, 2015; Bak \& Alladi, 2016; Yang, Yang \& Lust, 2011), such comparisons, carefully conducted and cautiously interpreted, can help contribute to a better understanding of bilingualism in particular and language and cognition in general.

\section{Supplementary material}

To view supplementary material for this article, please visit https://doi.org/10.1017/S1366728918000020

\section{References}

Abutalebi, J., Guidi, L., Borsa, V., Canini, M., Della Rosa, P. A., Parris, B. A., \& Weekes, B. S. (2015). Bilingualism provides a neural reserve for aging populations. Neuropsychologia, 69, 201-210. doi:10.1016/ j.neuropsychologia.2015.01.040

Bak, T. H. (2016). The impact of bilingualism on cognitive aging and dementia: Finding a path through a forest of confounding variables. Linguistic Approaches to Bilingualism, 6(1), 205-226. doi:10.1075/lab.15002.bak

Bak, T. H., \& Alladi, S. (2016). Bilingualism, dementia and the tale of many variables: Why we need to move beyond the Western World. Commentary on Lawton et al. (2015) and Fuller-Thomson (2015). Cortex, 74, 315-317. doi:10.1016/j.cortex.2015.04.025

Bak, T. H., Vega-Mendoza, M., \& Sorace, A. (2014). Never too late? An advantage on tests of auditory attention extends to late bilinguals. Frontiers in Psychology, 5, 16. doi:10.3389/fpsyg.2014.00485-

Bialystok, E., Craik, F. I. M., Klein, R., \& Viswanathan, M. (2004). Bilingualism, aging, and cognitive control: Evidence from the Simon Task. Psychology and Aging, 19(2), 290-303. doi:10.1037/0882-7974.19.2.290

Bokhorst-Heng, W. D., \& Caleon, I. S. (2009). The language attitudes of bilingual youth in multilingual Singapore. Journal of Multilingual and Multicultural Development, 30(3), 235-251. doi.:10.1080/01434630802510121

Clare, L., Whitaker, C. J., Martyr, A., Martin-Forbes, P. A., Bastable, A. J. M., Pye, K. L., Quinn, C., Thomas, E. M., Mueller Gathercole, V. C., \& Hindle, J. V. (2016). Executive control in older Welsh monolinguals and bilinguals. Journal of Cognitive Psychology, 28(4), 412426. doi:10.1080/20445911.2016.1148041

Costa, A., Hernández, M., Costa-Faidella, J., \& SebastiánGallés, N. (2009). On the bilingual advantage in conflict processing: Now you see it, now you don't. Cognition, 113(2), 135-149. doi:10.1016/j.cognition.2009.08.001
Costa, A., Hernández, M., \& Sebastián-Gallés, N. (2008). Bilingualism aids conflict resolution: Evidence from the ANT task. Cognition, 106(1), 59-86. doi:10.1016/j.cognition.2006.12.013

Duñabeitia, J. A., Hernández, J. A., Antón, E., Macizo, P., Estévez, A., Fuentes, L. J., \& Carreiras, M. (2014). The inhibitory advantage in bilingual children revisited: Myth or reality? Experimental Psychology, 61(3), 234-251. doi:10.1027/1618-3169/a000243

Dye, M. W. G., Green, C. S., \& Bavelier, D. (2009). The development of attention skills in action video game players. Neuropsychologia, 47, 1780-1789. doi:10.1016/j.neuropsychologia.2009.02.002

Fan, J., McCandliss, B. D., Sommer, T., Raz, A., \& Posner, M. I. (2002). Testing the efficiency and independence of attentional networks. Journal of Cognitive Neuroscience, 14(3), 340-347. doi:10.1162/089892902317361886

Foley, J. A. (Ed.). (1988). New Englishes: the case of Singapore. Singapore: Singapore University Press, National University of Singapore.

Foley, J. A. (1998). Code-switching and learning among young children in Singapore. International Journal of the Sociology of Language, 130(1998), 129-150.

Fuller-Thomson, E., \& Kuh, D. (2014). The healthy migrant effect may confound the link between bilingualism and delayed onset of Alzheimer's disease. Cortex, 52, 128130.doi:10.1016/j.cortex.2013.08.009

Green, D. W., \& Abutalebi, J. (2013). Language control in bilinguals: The adaptive control hypothesis. Journal of Cognitive Psychology, 25(5), 515-530. doi: $10.1080 / 20445911.2013 .796377$

Hartanto, A., \& Yang, H. (2016). Disparate bilingual experiences modulate task-switching advantages: A diffusion-model analysis of the effects of interactional context on switch costs. Cognition, 150, 10-19. doi:10.1016/j.cognition.2016.01.016

Hernández, M., Costa, A., Fuentes, L. J., Vivas, A. B., \& Sebastian-Galles, N. (2010). The impact of bilingualism on the executive control and orienting networks of attention. Bilingualism: Language and Cognition, 13(3), 315-325. doi:10.1017/S1366728909990010

Hindle, J. V, Martin-Forbes, P. A., Bastable, A. J. M., Pye, K. L., Martyr, A., Whitaker, C. J., Craik, F.I.M., Bialystock, E., Thomas, E.M., Mueller Gathercole, V.C., \& Clare, L. (2015). Cognitive reserve in Parkinson's Disease: The effects of Welsh-English bilingualism on executive function. Parkinson's Disease, 2015, 1-10. doi.:10.1155/2015/943572

Jiao, L., Liu, C., Wang, R., \& Chen, B. (2017). Working memory demand of a task modulates bilingual advantage in executive functions. International Journal of Bilingualism, 1-16. https://doi.org/10.1177/ 1367006917709097

Kamwangamalu, N. M., \& Lee, C.-L. (1991). ChineseEnglish code-mixing: a case of matrix language assignment. World Englishes, 10(3), 247-261. doi:10.1111/ j.1467-971X.1991.tb00159.x

Luk, G., \& Bialystok, E. (2013). Bilingualism is not a categorical variable: Interaction between language proficiency and usage. Journal of Cognitive Psychology, 25(5), 605-621. doi.:10.1080/20445911.2013.795574 
Morales, J., Calvo, A., \& Bialystok, E. (2013). Journal of Experimental Child Working memory development in monolingual and bilingual children. Journal of Experimental Child Psychology, 114(2), 187-202. https://doi.org/10.1016/j.jecp.2012.09.002

Morton, J. B., \& Harper, S. N. (2007). What did Simon say? Revisiting the bilingual advantage. Developmental Science, 10(6), 719-726. doi:10.1111/j.1467-7687.2007.00623.x

National Records of Scotland (2015). Scotland's Census 2011: Gaelic report (part 2). Retrieved from http://www. scotlandscensus.gov.uk/documents/analytical_reports/ Report_part_2.pdf

National University of Singapore, Registrar's Office. (2017a). Student Enrolment Statistics, Undergraduate studies 2016/2017. Retrieved from http://www.nus.edu.sg/ registrar/info/statistics/ug-enrol-20162017.pdf

National University of Singapore, Registrar's Office. (2017b). Student Enrolment Statistics, Graduate studies 2016/2017. Retrieved from http://www.nus.edu.sg/registrar/info/ statistics/gd-enrol-20162017.pdf

Ong, K., \& Zhang, L. (2010). Metalinguistic filters within the bilingual language faculty: A study of young EnglishChinese bilinguals. Journal of Psycholinguistic Research, 39, 243-272. doi:10.1007/s10936-009-9137-z

Paap, K. R., \& Greenberg, Z. I. (2013). There is no coherent evidence for a bilingual advantage in executive processing. Cognitive Psychology, 66(2), 232-258. doi:10.1016/j.cogpsych.2012.12.002

Paap, K. R., Johnson, H. A., \& Sawi, O. (2014). Are bilingual advantages dependent upon specific tasks or specific bilingual experiences? Journal of Cognitive Psychology, 26(6), 615-639. doi:10.1080/20445911.2014.944914

Paap, K. R., Johnson, H. A., \& Sawi, O. (2015). Bilingual advantages in executive functioning either do not exist or are restricted to very specific and undetermined circumstances. Cortex, 69, 265-278. doi:10.1016/j.cortex.2015.04.014

Poarch, G. J., \& van Hell, J. G. (2012). Executive functions and inhibitory control in multilingual children: Evidence from second-language learners, bilinguals, and trilinguals. Journal of Experimental Child Psychology, 113(4), 535551. doi.:10.1016/j.jecp.2012.06.013

Prior, A., \& Gollan, T. H. (2011). Good language-switchers are good task-switchers: Evidence from SpanishEnglish and Mandarin-English bilinguals. Journal of the International Neuropsychological Society, 17(4), 682-691. doi:10.1017/S1355617711000580

Prior, A., \& Macwhinney, B. (2010). A bilingual advantage in task switching. Bilingualism: Language and Cognition, 13(2), 253-262. doi:10.1017/s1366728909990526

Qu, L., Low, J. J. W., Zhang, T., Li, H., \& Zelazo, P. D. (2015). Bilingual advantage in executive control when task demands are considered. Bilingualism: Language and Cognition, 19(2), 1-17. doi:10.1017/S1366728914000376

Quacquarelli Symonds [QS] Top Universities. (2017). QS World University Rankings 2018. Retrieved from https://www.topuniversities.com/university-rankings/ world-university-rankings/2018
Raven, J. C., \& Foulds, G. A. (1962). Advanced Progressive Matrices. London: H.K. Lewis \& Co. Ltd.

Raven, J., Raven, J. C., \& Court, J. H. (1998). Manual for Raven's Progressive Matrices and Vocabulary Scales. Section 4: Advanced Progressive Matrices. Harcourt Assessment, Inc.

Robertson, I. H., Nimmo-Smith, I., Ward, T., \& Ridgeway, V. (1994). The Test of Everyday Attention. England: Thames Valley Test Company.

Rodriguez-Fornells, A., Krämer, U. M., Lorenzo-Seva, U., Festman, J., \& Münte, T. F. (2012). Self-assessment of individual differences in language switching. Frontiers in Psychology, 2, 1-15. doi.: 10.3389/fpsyg.2011.00388

Singapore Department of Statistics (2016). Population trends (Chapter 1: Population - Ethnic Composition). Retrieved from http://www.singstat.gov.sg/docs/default-source/ default-document-library/publications/publications_and_ papers/population_and_population_structure/population 2016.pdf

Tao, L., Marzecová, A., Taft, M., Asanowicz, D., \& Wodniecka, Z. (2011). The efficiency of attentional networks in early and late bilinguals: The role of age of acquisition. Frontiers in Psychology, 2, 1-19. doi:10.3389/fpsyg.2011.00123

The University of Edinburgh, Governance and Strategic Planning. (2017). 2016/2017 Student Factsheet (EndYear). Retrieved from http://www.docs.sasg.ed.ac.uk/ gasp/factsheet/StudentFactsheet31072017.pdf

The World Bank. (2017). World Bank analytical classifcations. Retrieved from http://databank.worldbank.org/ data/download/site-content/OGHIST.xls

Times Higher Education. (2017). World University Rankings, 2017. Retrieved from https://www.timeshighereducation. com/world-university-rankings.

United Nations Development Programme. (2015). Human development report (Statistical annex: Human development index and its components). Retrieved from http://hdr. undp.org/en/2015-report/download

Vega-Mendoza, M., West, H., Sorace, A., \& Bak, T. H. (2015). The impact of late, non-balanced bilingualism on cognitive performance. Cognition, 137, 40-46. doi:10.1016/j. cognition.2014.12.008

Verreyt, N., Woumans, E., Vandelanotte, D., Szmalec, A., \& Duyck, W. (2015). The influence of language-switching experience on the bilingual executive control advantage. Bilingualism: Language and Cognition, 19(1), 181-190. doi:10.1017/S1366728914000352

Wilms, I. L., Petersen, A., \& Vangkilde, S. (2013). Intensive video gaming improves encoding speed to visual shortterm memory in young male adults. Acta Psychologica, 142(1), 108-118. doi:10.1016/j.actpsy.2012.11.003

Xie, W., \& Cavallaro, F. (2016). Attitudes towards Mandarin-English bilingualism: A study of Chinese youths in Singapore. Journal of Multilingual and Multicultural Development, 37(6), 628-641. doi:10.1080/ 01434632.2015 .1122603

Yang, S., Yang, H., \& Lust, B. (2011). Early childhood bilingualism leads to advances in executive attention: Dissociating culture and language. Bilingualism: Language and Cognition, 14(3), 412-422. doi:10.1017/S1366728910000611 
Yow, W. Q., \& Li, X. (2015). Balanced bilingualism and early age of second language acquisition as the underlying mechanisms of a bilingual executive control advantage: Why variations in bilingual experiences matter. Frontiers in Psychology, 6, 1-12. doi:10.3389/fpsyg.2015. 00164 